\title{
Circulation of $\mathrm{Na}, \mathrm{Cl}$, and $\mathrm{Br}$ in the Tropical Marine Atmosphere
}

\author{
MARK A. KRITZ ${ }^{1}$ AND JACQUES RANCHER ${ }^{2}$
}

\author{
Centre des Faibles Radioactivités, Laboratoire Mixte CNRS-CEA, 91190 Gif-sur-Yvette, France
}

\begin{abstract}
Concentrations of $\mathrm{Na}, \mathrm{Cl}, \mathrm{Br}$, and $\mathrm{I}$ in aerosols and $\mathrm{Cl}, \mathrm{Br}$, and $\mathrm{I}$ in inorganic gases were measured in the marine atmosphere off the west African coast $\left(\sim 0^{\circ} \mathrm{N}, \sim 0^{\circ} \mathrm{W}\right)$ in June 1977 and used to estimate their mean lifetimes and rates of production. Mean concentrations (in micrograms per cubic meter) during an

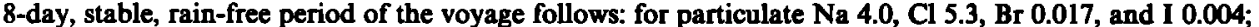
for inorganic gas $\mathrm{Cl} 1.0, \mathrm{Br} 0.012$, and $\mathrm{I} 0.013$. The results of a steady state analysis suggest a $\sim 3$-day mean residence time for the marine aerosol during the period of our observations, a $\sim 667 \mu \mathrm{g} \mathrm{m}^{-2} \mathrm{~d}^{-1}$ loss rate of $\mathrm{Cl}$ (probably as $\mathrm{HCl}$ ) from the marine aerosol, and a subsequent $\sim 2 \mathrm{f}$-day mean residence time in the marine atmosphere. A similar analysis for gaseous inorganic Br gave a $\sim 2 \frac{1}{2} \mu \mathrm{g} \mathrm{m} \mathbf{m}^{-2} \mathrm{~d}^{-1}$ mean loss rate from the marine aerosol and a $\sim 7$-day mean residence time. Computed dry deposition coefficients were (in centimeters per second) $\sim 0.4$ for the marine aerosol, $\sim 0.77$ for gaseous inorganic $\mathrm{Cl}$, and $\sim 0.24$ for gaseous inorganic Br.
\end{abstract}

\section{INTRODUCTION}

Over the open ocean the halogen budget of the marine atmosphere is dominated by oceanic sources and sinks. For $\mathrm{Cl}$ and $\mathrm{Br}$ the primary source is the marine aerosol, which is produced by the formation of small $(<100 \mu \mathrm{m})$ seawater droplets accompanying the bursting of air bubbles at the sea surface [Woodcock, 1953; Kientzler et al., 1954; Blanchard, 1963]. While the $\mathrm{Cl} / \mathrm{Na}$ ratio of these newly formed particles is that of seawater (1.8) [Buat-Menard, 1970; Wilkness and Bressan, 1972; Duce and Hoffman, 1976], measured values of this ratio in the marine aerosol are typically in the range 1.0-1.7 [Cauer, 1951; Chesselet et al., 1972; Martens et al., 1973]. This difference is generally attributed to the loss of a gaseous, Cl-bearing inorganic species (probably $\mathrm{HCl}$ ) from the marine aerosol following its dehydration or acidification [Eriksson, 1959; Robbins et al., 1959; Duce, 1969], which in turn is believed to account for the $\sim 1-3 \mu \mathrm{g} \mathrm{m}^{-3}$ concentrations of gaseous inorganic $\mathrm{Cl}$ observed in the marine atmosphere by Junge [1957], Duce et al. [1965], Chesselet et al. [1972], and others. There have been only two quantitative estimates of the mean residence time of this gaseous inorganic $\mathrm{Cl}$ in the troposphere: those of Rahn et al. [1976], who estimated a value of 21 days for continental air, and Chesselet et al. [1972], who estimated a half-life of about 8 hours for gaseous inorganic $\mathrm{Cl}$ in marine air which had been blown inland. For the marine atmosphere there exist only the qualitative estimates of Duce [1969], who discussed the factors governing the relative residence times of particulate and gaseous $\mathrm{Cl}$ and concluded that the mean residence time of the gaseous component of $\mathrm{Cl}$ was 'considerably longer' than that of the particulate form.

The $\mathrm{Br} / \mathrm{Na}$ ratio in the newly formed particles of the marine aerosol is also believed to be that of seawater $\left(6.2 \times 10^{-3}\right)$ [Duce and Hoffman, 1976]. A gaseous form of $\mathrm{Br}$ has also been observed in the marine atmosphere (in concentrations of about $0.5 \mu \mathrm{g} \mathrm{m}^{-3}$ as $\mathrm{Br}$ ) and has been attributed to a loss of $\mathrm{Br}_{2}(\mathrm{~g})$ from the marine aerosol following a photochemical oxidation [Duce et al., 1965]. Moyers and Duce [1972b] estimated the mean residence time of 'total' gaseous Br in the Hawaiian marine atmosphere to be 2-3 weeks; however, this figure was

\footnotetext{
${ }^{1}$ Now at Department of Chemistry, Drexel University, Philadelphia, Pennsylvania 19104.

${ }_{2}$ Now at Service de Physique, Université d'Abidjan, Abidjan, Ivory Coast.

Copyright $(\mathcal{1} 1980$ by the American Geophysical Union.
}

for the organic and inorganic forms taken together and thus is greater than that expected for the inorganic form(s) alone. Rahn et al. [1976] estimated an 8-day mean residence time for gaseous inorganic $\mathrm{Br}$ in the continental troposphere.

The behavior of $I$ in the marine atmosphere appears to be substantially different from that outlined above for $\mathrm{Br}$ and $\mathrm{Cl}$. Measured I/Na ratios in the marine aerosol are typically 100 1000 times greater than the seawater value [Miyake and Tsunogai, 1963; Duce et al., 1963]. Two tentative explanations have been advanced for this behavior: (1) a direct enrichment of $I$ on the aerosol occurring during the bubble-bursting-aerosol-forming process [Bolin, 1959] and/or (2) an uptake of a gaseous I-bearing species by the aerosol subsequent to its formation [Miyake and Tsunogai, 1963]. Lovelock et al. [1973] reported $\mathrm{CH}_{3} \mathrm{I}$ concentrations of $\left.\sim 1.2 \mathrm{ppt}(\sim 0.007 \mu \mathrm{g} \mathrm{I} \mathrm{m})^{-3}\right)$ over the North Atlantic, and Duce et al. [1965] and Moyers and Duce [1972a] observed 'gaseous I' concentrations of this same order in the Hawaiian marine atmosphere. Several oceanic sources of this gaseous I have been proposed, such as biological methylation for $\mathrm{CH}_{3} \mathrm{I}$ [Lovelock et al., 1973] or an oxidation or photooxidation at the sea surface, resulting in the liberation of $\mathrm{I}_{2}(\mathrm{~g})$ [Miyake and Tsunogai, 1963; Martens and Harriss, 1970; Seto and Duce, 1972]. Further discussion of these possibilities is found in the work of Duce and Hoffman [1976]. Photochemistry almost certainly plays an important role in the cycle of $\mathrm{I}$ (as well as Br) in the marine atmosphere, as was discussed by Zafiriou [1974].

\section{Sampling and analytical Procedures}

The sampling apparatus consisted of a two-stage filter holder containing, first, a 47-mm-diameter Nuclepore membrane ( $0.8-\mu \mathrm{m}$ hole diameter), which trapped the particles of the marine aerosol, followed by three 47-mm-diameter Whatman 41 cellulose filters in series, which had been impregnated with a $0.1 \mathrm{~N} \mathrm{LiOH}$ solution. This has been shown to trap effectively the inorganic halogen gases (such as $\mathbf{H C l}, \mathbf{H B r}, \mathrm{Br}_{2}$, etc.) which were of primary interest here, while passing the organic forms (such as $\mathrm{CH}_{3} \mathrm{Cl}, \mathrm{CCl}_{4}$, the Freons, etc.). The technique was developed by Rahn et al. [1976] at the Graduate School of Oceanography, University of Rhode Island, and a large part of our success here is due to their generosity and enthusiastic cooperation in sharing it with us.

Sampling was carried out aboard the French research vessel Capricorne in the Gulf of Guinea $\left(\sim 0^{\circ} \mathrm{N}, \sim 0^{\circ} \mathrm{W}\right)$ during the 
period May 30 to June 12, 1977. The sampling apparatus was mounted at the end of a 3-m-long boom extending from the bows of the vessel, approximately $8 \mathrm{~m}$ above the sea surface. The direction of the relative wind was monitored continuously, and power to the sampling pump cut off automatically when the relative wind shifted to abaft the beam. (However, this seldom occurred during the voyage.) Filters were changed and handled in a portable laminar flow bench, and extreme care was taken to prevent contamination. A nominal flow rate of $1 \mathrm{~m}^{-3} \mathrm{~h}^{-1}$ was used during the sampling periods, which had a nominal duration of 12 hours. Several procedural blanks, handled identically as the regular samples, were also taken. Procedural blank values for the Nuclepore membranes were as follows: $\mathrm{Na}$ was $1.3 \pm 0.1 \mu \mathrm{g} ; \mathrm{Cl}, 3.2 \pm 0.2 \mu \mathrm{g} ; \mathrm{Br}, 0.033 \pm$ $0.01 \mu \mathrm{g}$; and I, $0.035 \pm 0.01 \mu \mathrm{g}$. For the impregnated Whatman 41 filters, $\mathrm{Cl}$ was $4.5 \pm 0.4 \mu \mathrm{g} ; \mathrm{Br}, 0.033 \pm 0.01 \mu \mathrm{g}$; and $\mathrm{I}, 0.003$ $\pm 0.003 \mu \mathrm{g}$.

Analysis was by instrumental neutron activation, using the facilities of the Pierre Sue Laboratory of the Commissariat a l'énergie atomique (CEA) and the Centre National de la Recherche Scientifique (CNRS). These procedures are described by Rancher [1978].

\section{MaRine ObSERVATIONS}

Figure 1 shows the ship's track in the Gulf of Guinea. The particulate $\mathrm{Na}$ and the particulate and gaseous inorganic $\mathrm{Cl}$ concentrations obtained during the voyage are tabulated in Table 1. (The $\mathrm{Br}$ and I data were indicative of a diurnal exchange between the aerosol and gas phases and are presented and discussed in detail by Kritz and Rancher [1980]. The night sampling period generally extended from 1830 to 0700 the next morning, and the day period from 0730 to 1800 . One 24hour sample, sample 19, was taken. In addition to wind direction and speed (given in Table 1), air and sea temperatures, sea state, cloud cover, and barometric pressure were also logged at 3-hour intervals. Radon daughter concentrations were measured at 2-hour intervals, using the automatic device of Lambert and Polian [1968].

During the 14 days of the voyage the air temperature varied between $23.7^{\circ}$ and $26.3^{\circ} \mathrm{C}$, and the sea surface temperature between $23.8^{\circ}$ and $26.7^{\circ} \mathrm{C}$. Diurnal temperature variations ranged between $0^{\circ}$ and $0.8^{\circ} \mathrm{C}$. Cloud cover varied from 0 to $\frac{1}{2}$

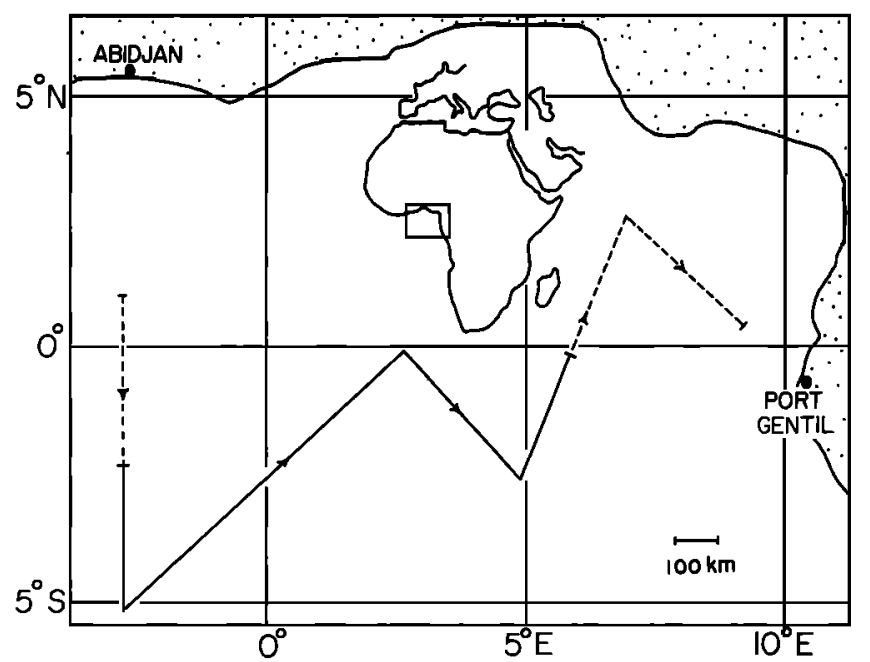

Fig. 1. Track of the RV Capricorne during the period of observations (May 30 to June 12, 1977). The 'marine' portion of the voyage (June 1-8) is indicated by the solid track. and, when present, consisted of scattered fair-weather cumulus of moderate vertical extension and/or thin stratocumulus. The altitude of the cloud base varied between 500 and $800 \mathrm{~m}$.

The first 10 days of the voyage (May 30 to June 8, corresponding to samples 1-20) were characterized by steady winds from the SSE sector, low radon daughter concentrations, and a complete lack of precipitation. This period ended with a brief rain shower on the afternoon of June 9, accompanied by a shift of the prevailing winds to the S-SSW sector and a marked rise in radon daughter concentrations. This occurred as the ship approached within $500 \mathrm{~km}$ of the coast and is interpreted as marking a transition from the stable, near-ideal marine situation prevailing during the first 10 days of the voyage to one which, while still basically marine, was subject to a significant continental influence.

Because of this behavior we have based our analysis on the 8-day period June 1-8 (samples 5-20), which we will refer to as the marine period. (Because night samples 2 and 4 were contaminated by seawater spray, the corresponding day samples ( 1 and 3 ) were also dropped from the analysis to preserve day-night symmetry.) All data obtained during the voyage appear in Table 1; however, the average concentrations listed in Table 2 are the arithmetic average of samples 5-20, taken during the marine period. Table 2 also contains the average particulate halogen/ $\mathrm{Na}$ and the $\mathrm{Cl}_{\text {tot }} / \mathrm{Cl}_{\mathrm{th}}$ and $\mathrm{Br}_{\mathrm{tot}} / \mathrm{Br}_{\mathrm{th}}$ ratios observed during the marine period. Here $\mathrm{Cl}_{\text {tot }}$ and $\mathrm{Br}_{\text {tot }}$ are simply the sum of the average particulate and gaseous inorganic concentrations, while $\mathrm{Cl}_{\mathrm{th}}$ and $\mathrm{Br}_{\mathrm{th}}$ are obtained by multiplying the mean particulate $\mathrm{Na}$ concentration by the seawater $\mathrm{Cl} / \mathrm{Na}$ and $\mathrm{Br} / \mathrm{Na}$ ratios and thus are indicative of the quantity of $\mathrm{Cl}$ and $\mathrm{Br}$ entering the marine atmosphere in conjunction with the formation of the marine aerosol. As is seen in the table, both the $\mathrm{Cl} / \mathrm{Na}$ and the $\mathrm{Br} / \mathrm{Na}$ ratios are less than the corresponding seawater values, reflecting the expected loss of $\mathrm{Cl}$ and $\mathrm{Br}$ from the marine aerosol. However, the clear and systematic difference between the $\mathrm{Cl}_{\text {too }} / \mathrm{Cl}_{\mathrm{th}}$ (0.88) and the $\mathrm{Br}_{\text {tot }} / \mathrm{Br}_{\text {th }}$ (1.17) ratios was not anticipated and seemed to suggest that the residence time of the gaseous inorganic $\mathrm{Cl}$ in the marine atmosphere was less than that of particulate $\mathrm{Cl}$, with the opposite situation holding for $\mathrm{Br}$. In an effort to understand quantitatively this aspect and other aspects of our data we formulated the model described below.

\section{Presentation of The Model}

The observations of Woodcock [1953], Durbin and White [1961], Morelli et al. [1974], and Gordon et al. [1977] and the theoretical analysis of Toba [1965] show the vertical distribution of the marine aerosol to be quasi-exponential, concentrations at $\mathbf{2 0 0 0} \mathrm{m}$ (the nominal height of the inversion and upper limit of the marine atmosphere) being typically less than $10 \%$ of those at sea level, and exchange with the overlying free atmosphere to be negligible. In view of this fact and the stable, unchanging meteorological conditions and absence of precipitation during the marine period of the voyage, we have approximated the marine atmosphere as a closed, steady state system, in which the mean local rates of production of the various constituents of interest are taken to be equal to their mean rate of removal (by dry deposition) at the sea surface.

For such a steady state system the throughput $\phi$, mean residence time $\tau$, and total quantity $Q$ of any given constituent are related as follows:

$$
\phi=Q / \tau
$$


TABLE 1. Observed Concentrations of Particulate $\mathrm{Na}$ and $\mathrm{Cl}$ and Gaseous Inorganic $\mathrm{Cl}$

\begin{tabular}{|c|c|c|c|c|c|c|}
\hline Sample & Date & $\begin{array}{c}\text { Wind } \\
\text { Speed, kn }\end{array}$ & $\begin{array}{c}\text { Wind } \\
\text { Direction }\end{array}$ & $\mathrm{Na}, \mu \mathrm{g} \mathrm{m}^{-3}$ & $\mathrm{Cl}, \mu \mathrm{g} \mathrm{m}^{-3}$ & $\mathrm{Cl} / \mathrm{Na}$ \\
\hline 1 & 30D & 16 & SSE & 3.95 & $\begin{array}{l}4.61 \\
1.09\end{array}$ & 1.17 \\
\hline 2 & $30 \mathrm{~N}$ & 12 & SE & & & \\
\hline 3 & 31D & 12 & SE & 4.27 & $\begin{array}{l}6.07 \\
1.18\end{array}$ & 1.42 \\
\hline 4 & $31 N$ & 14 & SE-ESE & & & \\
\hline 5 & 1D & 13 & SE & 9.01 & $\begin{array}{c}13.2 \\
0.81\end{array}$ & 1.47 \\
\hline 6 & $1 \mathbf{N}$ & 16 & SSE-SE & 5.50 & $\begin{array}{l}8.51 \\
1.16\end{array}$ & 1.56 \\
\hline 7 & 2D & 17 & SE & 5.54 & $\begin{array}{l}8.07 \\
0.96\end{array}$ & 1.46 \\
\hline 8 & $2 \mathrm{~N}$ & 13 & SE & 4.14 & $\begin{array}{l}5.25 \\
1.24\end{array}$ & 1.27 \\
\hline 9 & $3 \mathrm{D}$ & 13 & SSE-SE & 4.02 & $\begin{array}{l}4.75 \\
1.27\end{array}$ & 1.18 \\
\hline 10 & $3 \mathbf{N}$ & 14 & SE & 3.91 & $\begin{array}{l}5.60 \\
0.76\end{array}$ & 1.43 \\
\hline 11 & 4D & 13 & S-SSE & 2.27 & $\begin{array}{l}3.39 \\
0.74\end{array}$ & 1.49 \\
\hline 13 & $4 N$ & 12 & S-SSE & 3.01 & $\begin{array}{l}3.73 \\
0.87\end{array}$ & 1.24 \\
\hline 14 & 5D & 10 & SSE & 2.61 & $\begin{array}{l}4.18 \\
0.85\end{array}$ & 1.60 \\
\hline 15 & $5 N$ & 10 & $\mathbf{S}$ & 3.15 & $\begin{array}{l}4.04 \\
0.50\end{array}$ & 1.28 \\
\hline 16 & 6D & 6 & SE & 3.35 & $\begin{array}{l}4.07 \\
0.51\end{array}$ & 1.21 \\
\hline 17 & $6 N$ & 11 & SSE-SE & 2.83 & $\begin{array}{l}2.97 \\
1.22\end{array}$ & 1.05 \\
\hline 18 & 7D & 11 & SSE & 2.97 & $\begin{array}{l}2.88 \\
1.15\end{array}$ & 0.97 \\
\hline 19 & 7N8D & 10 & SSE & 2.71 & $\begin{array}{l}2.42 \\
1.60\end{array}$ & 0.89 \\
\hline 20 & $8 \mathbf{N}$ & 7 & SSE & 6.37 & $\begin{array}{l}8.74 \\
1.08\end{array}$ & 1.37 \\
\hline 21 & 9D & 9 & SSE-SSW & 4.11 & $\begin{array}{l}5.22 \\
1.92\end{array}$ & 1.27 \\
\hline 23 & $9 \mathrm{~N}$ & 6 & SE & 0.99 & $\begin{array}{l}1.40 \\
1.46\end{array}$ & 1.41 \\
\hline 24 & 10D & 13 & S-SSW & 3.01 & $\begin{array}{l}4.16 \\
0.54\end{array}$ & 1.38 \\
\hline 25 & $10 \mathrm{~N}$ & 16 & SSW & 1.91 & 1.84 & 0.96 \\
\hline 26 & $11 \mathrm{D}$ & 16 & S-SSW & 4.15 & $\begin{array}{l}3.67 \\
1.95\end{array}$ & 0.88 \\
\hline 27 & $11 N$ & 13 & $\mathbf{S}$ & 3.63 & $\begin{array}{l}2.80 \\
1.88\end{array}$ & 0.77 \\
\hline 28 & 12D & 13 & $\mathbf{S}$ & 2.62 & $\begin{array}{l}1.68 \\
1.37\end{array}$ & 0.64 \\
\hline
\end{tabular}

These observations were made during the period May 30 to June 12, 1977 (D indicates a day sample, and $\mathbf{N}$ night (see text)). The ship's track during the voyage is shown in Figure 1 . The top line of data for each sample lists particulate concentrations. The second line (for $\mathrm{Cl}$ ) lists the concentration of the gaseous inorganic component. Overall uncertainties are $+8 \%$. Samples 12 and 22 were procedural blanks. Results for $\mathrm{Br}$ and I are presented elsewhere [Kritz and Rancher, 1980].

Applying this relation to the marine aerosol for the conditions obtaining during the marine period of our observations results in

$$
\phi_{a}=C \tilde{H} / \tau
$$

where $\phi_{a}$ is the rate of production of the marine aerosol per unit area of sea surface and $C H$ is the total quantity of aerosol in a $1-\mathrm{m}^{2}, 2000-\mathrm{m}$-high column. Here $C$ is the mean measured aerosol concentration $8 \mathrm{~m}$ above the sea surface, and $\bar{H}$ is an 'effective height,' or scale factor, relating the vertical distribu- tion of the marine aerosol, its concentration at $8 \mathrm{~m}$, and the total quantity of aerosol in a $1-\mathrm{m}^{2}$ column of the marine atmosphere. On the basis of the vertical profiles of particulate $\mathrm{Na}$ obtained by Chesselet et al. [1972], Morelli et al. [1974], and Gordon et al. [1977] we have taken $1000 \mathrm{~m}$ as the nominal value for $\bar{H}$ during the (rain free) period of our observations; that is, the quantity of $\mathrm{Na}$ (the standard reference element for the marine aerosol) in a $1-\mathrm{m}^{2}$ column extending $2000 \mathrm{~m}$ above the sea surface (determined by integrating the aforementioned vertical profiles) is approximately equal to the product of 1000 $\mathrm{m}$ and the concentration of $\mathrm{Na} 8 \mathrm{~m}$ above the sea surface. 
TABLE 2. Mean Concentrations During the Marine Period of Observations

\begin{tabular}{lllll}
\hline & $\mathrm{Na}$ & $\mathrm{Cl}$ & $\mathrm{Br}$ & $\mathrm{I}$ \\
\hline Particulate & & & & \\
Concentration, $\mu \mathrm{g} \mathrm{m}^{-3}$ & $4.0(1.8)$ & $5.3(2.9)$ & 0.017 & 0.004 \\
Ratio, $(\mathrm{X} / \mathrm{Na})$ observed & & $1.3(0.2)$ & 0.0042 & 0.001 \\
Ratio, (X/Na) seawater & & 1.8 & 0.0062 & 0.000059 \\
Gaseous inorganic & & $1.0(0.3)$ & 0.012 & 0.013 \\
$\quad$ Concentration, $\mu \mathrm{g} \mathrm{m}^{-3}$ & & 0.88 & 1.17 & \\
Ratio $\mathrm{X}_{\text {tot }} / \mathrm{X}_{\text {th }}$ & & & \\
\hline
\end{tabular}

Mean concentrations listed above are the arithmetic averages of observations during the marine portion of the voyage (samples 5-20). Values in parentheses are standard deviations, derived from the data in Table 1.

* $X_{\text {tot }}=X_{\text {particulate }}+X_{\text {gaseous inorganic; }} X_{\text {th }}=\mathrm{Na}_{\text {partuculate }}(X / \mathrm{Na})_{\text {seawaler }}$

The rate of removal of aerosol by dry deposition at the sea surface may be described by the relation

$$
\phi_{r}=v_{g} C
$$

where $C$ is the mean measured concentration of aerosol $8 \mathrm{~m}$ above the sea surface, as before, and $v_{g}$ is the dry deposition coefficient, or deposition velocity.

For the conditions of our observations (the absence of precipitation, steady meterological situation, and presumed limited upward mixing out of the marine atmosphere) these two fluxes may be equated:

$$
\phi=(C \tilde{H} / \tau)=v_{g} C
$$

Given the 1000 -m value for $\bar{H}$ obtained above and the average concentrations observed during the marine portion of the voyage, this leaves three unknowns in the equation: the rate of production of aerosol at the sea surface, $\phi$; its mean residence time in the marine atmosphere, $\tau$; and the magnitude of the deposition velocity $v_{g}$ for its reabsorption at the sea surface. However, the form of (3) is such that fixing any one of these quantities uniquely determines the values of the other two. While all three of these factors have been studied, our knowledge of the production rate and residence time of the marine aerosol seems to be most advanced. Here we have chosen to work with the mean residence time of the marine aerosol, which following the work of Junge [1972] and Moore et al. [1974] would be expected to be between 2 and 3 days.

\section{NUMERICAL RESULTS}

We have solved (3) using various assumed values for the mean residence time of the marine aerosol, and we illustrate the computation below, using a 3-day figure, which gave the best agreement with the various external constraints on the results.

Solving (3) by using this 3-day mean residence time, the measured mean Na concentration of $4.0 \mu \mathrm{g} \mathrm{m}^{-3}$ (c.f. Table 2), and a value of $1000 \mathrm{~m}$ for $H$ leads to a computed $\mathrm{Na}$ production rate of $\sim 1330 \mu \mathrm{g} \mathrm{d} \mathrm{d}^{-1}$ per square meter of sea surface. (The corresponding rate of total sea salt production may be obtained by multiplying this rate by 3.07.) Next, the difference between the $\mathrm{Cl} / \mathrm{Na}$ ratio of the newly formed marine aerosol (1.8) and the mean $\mathrm{Cl} / \mathrm{Na}$ ratio observed in the marine atmosphere (1.3), together with the aerosol production rate determined above, results in a computed $\mathrm{Cl}$ loss rate from the marine aerosol of $\sim 667 \mu \mathrm{g} \mathrm{m}^{-2} \mathrm{~d}^{-1}$. As was mentioned earlier, this probably occurs as a loss of $\mathrm{HCl}(\mathrm{g})$ and is believed to be the source of the gaseous inorganic $\mathrm{Cl}$ present in the marine atmosphere [Duce, 1969].

While there have been several studies of the variation with altitude of the marine aerosol, the only comparable study for gaseous inorganic $\mathrm{Cl}$ is that on Junge [1957], who found (at Hawaii) that the concentration of gaseous inorganic $\mathrm{Cl}$ above the trade wind inversion was approximately half of that observed at sea level. This implies that the scale height of gaseous inorganic $\mathrm{Cl}$ is greater than that of the marine aerosol (whose concentrations above the trade wind inversion are typically only a few percent of the nominal sea level value); thus in our analysis we have taken a value of $1500 \mathrm{~m}$ for the effective heights $\vec{H}$ of gaseous inorganic $\mathrm{Cl}$ and $\mathrm{Br}$, as opposed to the $1000-\mathrm{m}$ value taken for the marine aerosol. With this assumption, and, again, that of no significant loss by upward mixing out of the marine boundary layer, writing (3) in terms of gaseous inorganic $\mathrm{Cl}$ and solving by using the mean of our observations during the marine period lead to a calculated deposition velocity of $\sim 0.77 \mathrm{~cm} \mathrm{~s}^{-1}$ and a mean residence time of $\sim 2 \frac{1}{4}$ days.

Similar computations may be made for $\mathrm{Br}$ and yield a mean loss rate of gaseous inorganic $\mathrm{Br}$ from the marine aerosol of $\sim 2 \frac{1}{2} \mu \mathrm{g} \mathrm{m}^{-2} \mathrm{~d}^{-1}$, a mean residence time in the marine atmosphere of $\sim 7$ days, and a deposition velocity of $\sim 0.24 \mathrm{~cm} \mathrm{~s}^{-1}$. The results are tabulated in Table 3.

Given the form of (3), it is evident that the magnitudes of the production rates, residence times, and deposition velocities computed above are directly dependent on the values assumed for the mean residence time and effective height of the reservoirs. However, as is clear from the discussion which follows, these values cannot be varied arbitrarily without adversely affecting the external agreement and internal self-consistency of the results.

\section{Discussion}

Production rate of the marine aerosol. The most thorough discussion and analysis of the production rate of the marine

TABLE 3. Results of the Steady State Analysis

\begin{tabular}{lccc}
\hline & $\begin{array}{c}\text { Mean } \\
\text { Residence } \\
\text { Time, } \\
\text { days }\end{array}$ & $\begin{array}{c}\text { Production } \\
\text { Rate, } \\
\mu \mathbf{m ~ m}^{-2} \mathbf{d}^{-1}\end{array}$ & $\begin{array}{c}\text { Dry } \\
\text { Deposition } \\
\text { Velocity, } \\
\text { cm s s }^{-1}\end{array}$ \\
\hline Particulate $\mathrm{Na}$ & 3 & 1330 & 0.39 \\
Gaseous inorganic $\mathrm{Cl}$ & $2 \frac{1}{4}$ & 667 & 0.77 \\
Gaseous inorganic $\mathrm{Br}$ & $7 \frac{1}{4}$ & 2.5 & 0.24 \\
\hline
\end{tabular}

The analysis was based on the assumption of a 3-day mean residence time and $1000-\mathrm{m}$ effective height for the marine aerosol and $1500 \mathrm{~m}$ for gaseous inorganic $\mathrm{Cl}$ and $\mathrm{Br}$ (see text) and was made by using the arithmetic average of data observed during the marine portion of the observations, as given in Table 2. Mean wind speed during this period was $12 \mathrm{kn}\left(6 \mathrm{~m} \mathrm{~s}^{-1}\right)$. 
aerosol is probably that of Blanchard [1963], who for a 12-kn $\left(6 \mathrm{~m} \mathrm{~s}^{-1}\right.$ ) wind (that obtaining during the marine period of our voyage) estimates the sea salt flux to be $\sim 4400 \mu \mathrm{g} \mathrm{m} \mathrm{m}^{-2} \mathrm{~d}^{-1}$, equivalent to $\sim 1400 \mu \mathrm{g} \mathrm{m}^{-2} \mathrm{~d}^{-1}$ as $\mathrm{Na}$. As is seeen from the preceding computation, our computed $\mathrm{Na}$ flux of $\sim 1330 \mu \mathrm{g}$ $\mathrm{m}^{-2} \mathrm{~d}^{-1}$ is in good agreement with Blanchard's [1963] estimated flux.

Deposition velocity of gaseous inorganic $\mathrm{Cl}$ and $\mathrm{Br}$. As was mentioned earlier, it is generally assumed that the gaseous inorganic $\mathrm{Cl}$ in the marine atmosphere is present in the form of $\mathrm{HCl}$. While there have been no experimental studies of the rate of exchange of $\mathrm{HCl}$ across the air-sea interface, it is possible to estimate a deposition velocity by extrapolation from the results available for other gases.

For gases which are highly soluble in seawater the rate-limiting step in the air-sea exchange is thought to be molecular diffusion in a thin $(\sim 1 \mathrm{~mm})$ layer of stagnant air just above the ocean surface (H. U. Sverdrup, quoted by Defant [1961]). By following the treatment of Bolin [1960] and Liss and Slater [1974] the coefficient governing the exchange across this stagnant layer (the deposition velocity) may be expressed as the ratio $D / z$, where $D$ is the coefficient of molecular diffusion (in air) of the gas in question and $z$ is the thickness of the stagnant layer. Thus if the deposition velocity is known for one soluble gas, its value for a second will be directly proportional to their relative coefficients of molecular diffusion in air or, if these coefficients are not known, approximately inversely proportional to the ratio of the square root of their respective molecular weights.

Using this technique, Liss and Slater [1974] estimated the deposition velocities across the air-sea interface for a number of soluble gases, keying their computation to the experimental results of Schooley [1969] for water vapor. In this way a deposition velocity of $\sim 0.6 \mathrm{~cm}^{-1}$ is obtained for $\mathrm{HCl}(\mathrm{g})$, in reasonable agreement with the $\sim 0.77 \mathrm{~cm} \mathrm{~s}^{-1}$ value for gaseous inorganic $\mathrm{Cl}$ resulting from our data and analysis.

In a similar manner a valuable check on both the internal consistency of the model and our results can be obtained by an intercomparison of the deposition velocities that we obtained for gaseous inorganic $\mathrm{Cl}$ and $\mathrm{Br}$. While experimental values of these velocities are not yet available, it is possible, by using the theoretical approximations outlined above, to determine the ratio of the theoretically estimated deposition velocities for gaseous inorganic $\mathrm{Cl}$ and $\mathrm{Br}$. The molecular weight of the most probable form of gaseous inorganic $\mathrm{Cl}$ in the marine atmosphere, $\mathrm{HCl}$, is 36.5 . While the identity of the corresponding species of gaseous inorganic $\mathrm{Br}$ is not known, its molecular weight probably falls between that of $\mathrm{HBr}(81)$ and $\mathrm{Br}_{2}$ (160), so that the theoretical ratio of the deposition velocity for gaseous inorganic $\mathrm{Cl}$ and $\mathrm{Br}$ is expected to be between about 0.5 and 0.7 . Given this range and the theoretical estimate derived above for the deposition velocity of $\mathrm{HCl}(\mathrm{g})$, the corresponding range of theoretically estimated values for the deposition velocity of gaseous inorganic $\mathrm{Br}$ is seen to be 0.3 $0.4 \mathrm{~cm} \mathrm{~s}^{-1}$.

As is seen from Table 3, our result for the deposition velocity of gaseous inorganic $\mathrm{Br}$ is $\sim 0.24 \mathrm{~cm} \mathrm{~s}^{-1}$, somewhat outside the expected range of $0.3-0.4 \mathrm{~cm} \mathrm{~s}^{-1}$. However, this may be an artifact of the large diurnal variations, mentioned earlier, in the concentrations of particulate and gaseous inorganic $\mathrm{Br}$ or may be indicative of the existence of a significant liquid phase transfer resistance for the gaseous $\mathrm{Br}$ species at the sea surface.
Deposition velocity of the marine aerosol. In considering the removal of particles at the sea surface by dry deposition the stagnant boundary layer concept is still valid, but in addition to Brownian diffusion of the particles in the layer (corresponding to the molecular diffusion of gas molecules), inertial effects and gravitational sedimentation are also important, so that the variables of particle size and density must also enter the analysis. While much excellent work has been done [c.f. Sehmel and Sutter, 1974], the theoretical and experimental problems are more complex and difficult, and our knowledge is less advanced, than in the analogous case for soluble gases. For these reasons we have not attempted to compare our results with the limited information available but instead present the aerosol deposition velocities derived from our analysis for whatever value they may have to those primarily concerned with this aspect of the problem. (The aerosol particle size distribution determined during the voyage is given in Table 4.)

Residence times of gaseous inorganic $\mathrm{Cl}$ and $\mathrm{Br}$. Given the 3-day mean residence time for the marine aerosol used thus far in our analysis and the absence of precipitation during the marine period of the voyage, the mean residence time of gaseous inorganic $\mathrm{Cl}$ in the tropical marine atmosphere was found to be $\sim 2 \frac{1}{4}$ days, while that of gaseous inorganic $\mathrm{Br}$ was $\sim 7$ days. Thus (for the condition obtaining at the time) the mean residence time of gaseous inorganic $\mathrm{Cl}$ was found to be approximately equal to (or perhaps slightly less than) that of the marine aerosol, while that of gaseous inorganic $\mathrm{Br}$ was approximately twice as long.

As was mentioned earlier, Duce [1969] suggested that the mean residence time of gaseous (inorganic) $\mathrm{Cl}$ in the marine atmosphere was 'considerably greater' than that of particulate $\mathrm{Cl}$. The apparent discrepancy between this suggestion and the present results may arise from the fact that many of the observations [Junge, 1957; Duce et al., 1965] on which Duce's [1969] estimate was based were made in Hawaii, in locations where locally produced marine aerosols (in the surf zone) were a recognized problem. In addition, unlike the present data set (which was obtained on a ship, in a stable, purely marine situation), many of these earlier data show a high degree of dayto-day variation, reflecting the variable conditions obtaining at the time. Thus while Duce's [1969] estimate was warranted for the data available at the time (or perhaps is in fact correct for the marine atmosphere near Hawaii), the present data set suggests, for the time and place of our observations, that the residence times of the marine aerosol and gaseous inorganic $\mathrm{Cl}$ were essentially equal.

Similarly, our $\sim 7$-day result for the mean residence time of gaseous inorganic $\mathrm{Br}$ is considerably less than the 2- to 3-week estimates of Moyers and Duce [1972b]. However, their gaseous

TABLE 4. Normalized Particle Size Distributions

\begin{tabular}{ccc}
\hline Impactor Stage & $\begin{array}{c}\text { Estimated Mean } \\
\text { Radius, } \mu \mathrm{m}\end{array}$ & Percentage \\
\hline 6 & 0.3 & 3 \\
5 & 0.6 & 9 \\
4 & 1.2 & 10 \\
3 & 2.4 & 38 \\
2 & 5 & 22 \\
1 & $>8$ & 5 \\
\hline
\end{tabular}

These results were obtained by using a Scientific Advances model CI-S-6 impactor and are presented in terms of mass. The sample was collected during the period 1730, June 6, to 1800, June 7, 1977. 
samples were collected on activated charcoal, which is known to trap effectively not only the inorganic but also the organic gaseous halogens subsequently shown to be present in the marine atmosphere [Rahn et al., 1976]. We have found the mean ratio of organic to inorganic $\mathrm{Br}$ in the marine atmosphere to be about 2:1 (J. Rancher et al., unpublished data, 1978), which could account for the longer residence times estimated by Moyers and Duce [1972b] for total gaseous Br.

Production rates of gaseous inorganic $\mathrm{Cl}$ and $\mathrm{Br}$. For the 3day aerosol mean residence time and $1000-\mathrm{m}$ effective height used in our analysis the loss rate of gaseous inorganic $\mathbf{C l}$ and $\mathrm{Br}$ from the marine aerosol were computed to be $\sim 667$ and $\sim 2 \frac{1}{2} \mu \mathrm{g} \mathrm{m}^{-2} \mathrm{~d}^{-1}$, respectively. These figures represent, to our knowledge, the first direct, quantitative computation of these rates. As was discussed earlier, they were determined on the basis of our calculated flux of the marine aerosol through the marine atmosphere and the observed differences between the $\mathrm{Cl} / \mathrm{Na}$ and $\mathrm{Br} / \mathrm{Na}$ ratios of the marine aerosol and those of seawater. In this work the mean observed $\mathrm{Cl} / \mathrm{Na}$ ratio was 1.3. However, while Buat-Menard et al. [1974] reported a similar ( 1.4) ratio for an earlier series of observations in the Gulf of Guinea, R. Chesselet (personal communication, 1979) has observed consistently higher ratios $(\sim 1.6)$ in numerous mid-Atlantic measurements, and the six studies cited in the review of Duce and Hoffman [1976] have a mean $\mathrm{Cl} / \mathrm{Na}$ ratio of $\sim 1.65$. These differences probably arise from the different meterological situations and/or the dominance of different $\mathrm{Cl}$ loss mechanisms in different oceanic regions and caution against the premature extrapolation of these production rates to a global scale.

Iodine. As was mentioned earlier, the behavior of $I$ in the marine atmosphere appears to be qualitatively different from that of $\mathrm{Cl}$ and $\mathrm{Br}$; in fact, to our knowledge, none of the models proposed thus far are capable of explaining all aspects of the information and data presently available. Even so, the present results can be used to set quantitative limits on some of the individual processes which might be suggested as part of such a model. For example, if the observed large enhancements of the $\mathrm{I} / \mathrm{Na}$ ratio of the marine aerosol (relative to seawater) are attributed to the absorption of a gaseous form of I by the aerosol subsequent to its formation, a lower limit for the requisite rate of this uptake (during the period of our observations) can be set by multiplying our observed particulate $\mathrm{I} / \mathrm{Na}$ ratio by our derived particulate $\mathrm{Na}$ production rate. This gives a net I uptake rate of $\sim 1.3 \mu \mathrm{g} \mathrm{m}^{-2} \mathrm{~d}^{-1}$, which presumably would also be the minimum net rate at which a gaseous species of I would have to be released from the sea surface to account, via this mechanism, for the observed enrichment.

Effect of other choices for $\tau$ and $\bar{H}$. While the stability of the meterological conditions probably resulted in $\tau$ and $\bar{H}$ of the marine aerosol being fairly constant during the marine period of our observations, their actual local quantitative values could easily have deviated somewhat from the mean, global values [c.f. Junge, 1972] estimated for these quantities. Thus while the use of 3 days for the mean residence time of the marine aerosol and $1000 \mathrm{~m}$ for its effective height happened to result in the best fit of our results with the various independent estimates of aerosol production rate, etc., the results of the analysis do not rule out, say, a 4-day figure for the mean residence time or an 800 - or a 1200 -m value for the effective height. For example, following the computational procedures outlined earlier, the use of a 4-day assumed value for $\tau$ (in place of the 3-day value used thus far) would shift the com- puted $\mathrm{Na}$ production rate to $1000 \mu \mathrm{g} \mathrm{m}^{-2} \mathrm{~d}^{-1}$ (in place of the $1330 \mu \mathrm{g} \mathrm{m}^{-2} \mathrm{~d}^{-1}$ value obtained by using 3 days), which is still in reasonable agreement with Blanchard's [1963] estimate, and would lead to a calculated deposition velocity for gaseous inorganic $\mathrm{Cl}$ which would still be in reasonable agreement with the theoretical estimate obtained by using the techniques of Liss and Slater [1974]. Similarly, taking the same value (1000 m) for the effective heights of the marine aerosol and gaseous inorganic $\mathrm{Cl}$ and $\mathrm{Br}$, while not affecting the computed production rates or deposition velocities for these gases, would reduce their computed residence times to $\sim 1 \frac{1}{2}$ and $\sim 5$ days, respectively.

In performing computations using various assumed values for $\tau$ and $\bar{H}$, two consistent results have been observed. First, the values of $\tau$ and $\bar{H}$ assumed for the marine aerosol may be varied by about $\pm 50 \%$ from the 3-day, 1000 -m nominal value before the resultant computed values of aerosol flux and gaseous inorganic $\mathrm{Cl}$ deposition velocity start to come into serious disagreement with the independent estimates of these quantities. Second, while such variations cause corresponding changes in the resultant computed production rates of particulate $\mathrm{Na}$ and gaseous inorganic $\mathrm{Cl}$ and $\mathrm{Br}$, the relative relationship between their residence times in the marine atmosphere remains constant.

\section{SUMMARY AND CONCLUSIONS}

By using our measurements of the concentrations of particulate $\mathrm{Na}, \mathrm{Cl}, \mathrm{Br}$, and $\mathrm{I}$ and gaseous inorganic $\mathrm{Cl}, \mathrm{Br}$, and $\mathrm{I}$ in the tropical marine atmosphere a steady state analysis has been made of the fluxes, residence times, and dry deposition velocities obtaining for these species at the time. Some of these computed results have been shown to be in good agreement with certain earlier estimates of individual quantities: in particular, our derived flux of the marine aerosol is in good agreement with Blanchard's [1963] estimates, and our computed deposition velocities for gaseous inorganic $\mathrm{Cl}$ and $\mathrm{Br}$ are in good agreement with the theoretical values obtained by using the techniques of Liss and Slater [1974]. In addition, new estimates of the loss rates of $\mathrm{Cl}$ and $\mathrm{Br}$ from the marine aerosol, and the subsequent mean residence times of these gases in the marine atmosphere have been obtained. These results were obtained by using a 3-day mean residence time for the marine aerosol in the analysis, based on Junge's [1972] and Moore et al.'s [1974] 2- to 3-day estimated value.

The fact that these various independent estimates can be simultaneously accommodated in a simple, straightforward analysis is an important confirmation of their validity and that of the concepts underlying our computations and lends strong support to the other, previously undetermined results of the analysis, that is, the fluxes and residence times of gaseous inorganic $\mathrm{Cl}$ and $\mathrm{Br}$ and the dry deposition velocity of the marine aerosol, as summarized in Table 2.

In considering and using the results of this work, however, two factors should be borne in mind. First, our analysis has not explicitly considered the role of gaseous organic $\mathrm{Cl}$ and $\mathrm{Br}$ compounds. While the total concentrations of these species (expressed in terms of the quantities of $\mathrm{Cl}$ or $\mathrm{Br}$ present) in the marine atmosphere are of the same order as those of gaseous inorganic $\mathrm{Cl}$ and $\mathrm{Br}$ (M. A. Kritz and J. Rancher, unpublished data, 1978), their apparent relative inertness in the troposphere implies that their contributions to the fluxes considered here are small and thus should not materially affect our results. 
Second, our study was made in the tropical marine atmosphere during an 8-day-long stable period characterized by strong insolation, moderate $\left(12 \mathrm{kn}\left(6 \mathrm{~m} \mathrm{~s}^{-1}\right)\right)$ winds, an average air temperature of $25^{\circ} \mathrm{C}$, and the absence of precipitation and significant continental influences. Because this kind of situation is somewhat atypical, it might be asked if some of the results might not also be atypical. However, what is unusual here is not the conditions per se that obtained during the period of stability (except for the absence of precipitation) but rather the 8 consecutive days during which the meterological situation was both unchanging and well characterized. The main effect of this stability, so far as our analysis is concerned, was to simplify the situation enough that an analysis was possible. Thus most of the rates and coefficients determined here should apply in similar meteorological conditions, irrespective of the duration of that particular situation.

Acknowledgments. The authors would like to thank J. Labyrie, director of the Centre des Faibles Radioactivités, and R. Chesselet, head of the Space-Oceans-Atmospheres Group, for their hospitality and support while the work was being done. We also wish to thank $R$. Chesselet, R. Duce, and J. Winchester for helpful and enjoyable discussions and constructive suggestions, and we wish to thank $C$. Lambert and the staff of the Pierre Sue Laboratorie d'Analyse par Activation for their helpful cooperation. Financial support for this work was provided by the laboratory, the CEA, and the CNRS.

\section{REFERENCES}

Blanchard, D., Electrification of the atmosphere by particles from bubbles in the sea, Progr. Oceanogr., $1,73,1963$.

Bolin, B., Note on the exchhange of iodine between the atmosphere, land and sea, Int. J. Air Pollut., 2, 127, 1959.

Bolin, B., On the exchange of carbon dioxide between the atmosphere and the sea, Tellus, 12, 274, 1960.

Buat-Menard, P., Contribution a l'etude du cycle géochimique du chlore d'origine marine, thèse de troisième cycle, Fac. des Sci., Paris, 1970.

Buat-Menard, P., J. Morelli, and R. Chesselet, Water-soluble elements in atmospheric particulate matter over tropical and equatorial Atlantic, J. Rech. Atmos., 8, 661, 1974.

Cauer, M., Some problems of atmospheric chemistry, in Compendium of Meteorology, 1126 pp., American Meterological Society, Boston, Mass., 1951.

Chesselet, R., M. Morelli, and P. Buat-Menard, Some aspects of the geochemistry of marine aerosols, Proceedings of Nobel Symposium 20, in The Changing Chemistry of the Oceans, edited by D. Dyrssen and D. Jagner, p. 92, Wiley-Interscience, New York, 1972.

Defant, A., Physical Oceanography, vol. 1, Pergamon, New York, 1961.

Duce, R. A., On the source of gaseous chlorine in the marine atmosphere, J. Geophys. Res., 74, 4579, 1969.

Duce, R. A., and E. J. Hoffman, Chemical fractionation at the air/sea interface, Annu. Rev. Earth Planet. Sci., 4, 187, 1976.

Duce, R. A., J. T. Wasson, J. W. Winchester, and F. Burns, Atmospheric iodine, bromine, and chlorine, J. Geophys. Res., 68, 3943, 1963.

Duce, R. A., J. W. Winchester, and T. W. Van Nahl, Iodine, bromine, and chlorine in the Hawaiian marine atmosphere, J. Geophys. Res., $70,1775,1965$.

Durbin, W. G., and G. D. White, Measurements of the vertical distribution of atmospheric chloride particles, Tellus, 13, 260, 1961.

Eriksson, E., The yearly circulation of chloride and sulfur in nature; meteorological, geochemical and pedological implications, 1, Tellus, 11, 375, 1959.
Gordon, C. M., E. C. Jones, and R. E. Larson, The vertical distribution of particulate $\mathrm{Na}$ and $\mathrm{Cl}$ in a marine atmosphere, $J$. Geophys. Res., 82, 988, 1977.

Junge, C. E., Chemical analysis of aerosols particles and of trace gases on the island of Hawaii, Tellus, 9, 528, 1957.

Junge, C. E., Our knowledge of the physico-chemistry of aerosols in the undisturbed marine environment, J. Geophys. Res., 77, 5183, 1972.

Kientzler, C. F., A. Arons, D. Blanchard, and A. Woodcock, Photographic investigation of the projection of droplets by bubbles bursting at a water surface, Tellus, 6, 1, 1954.

Kritz, M. A., and J. Rancher, Diurnal variations of $\mathrm{Br}$ and $\mathrm{I}$ in the tropical marine atmosphere, submitted to J. Geophys. Res., 1980.

Lambert, G., and G. Polian, Mesure de la radioactivité atmosphérique naturelle par appareils alpha semi-automatiques, report, Centre des Faibles Radioactiv., Centre Nat. de la Rech. Sci., Gifsur-Yvette, France, 1968.

Liss, P. S., and P. G. Slater, Flux of gases across the air-sea interface, Nature, 247, 181, 1974.

Lovelock, J. E., R. J. Maggs, and R. J. Wade, Halogenated hydrocarbons in and over the Atlantic, Nature, 241, 194, 1973.

Martens, C. S., and R. C. Harriss, Mechanisms of iodine injection from the sea surface in precipitation scavenging, $A E C$ Symp. Ser., 22, 319, 1970.

Martens, C. S., J. J. Wesolowski, R. C. Harriss, and R. Kaifer, Chlorine loss from Puerto Rican and San Francisco Bay area marine aerosols, J. Geophys. Res., 78, 8778, 1973.

Miyake, Y., and S. Tsunogai, Evaporation of iodine from the ocean, J. Geophys. Res., 68, 3989, 1963.

Moore, H. E., S. E. Poet, E. A. Martell, and M. H. Wilkening, Origin of ${ }^{222} \mathrm{Rn}$ and its long-lived daughters in air over Hawaii, $J$. Geophys. Res., 79, 5019, 1974.

Morelli, J., P. Buat-Menard, and R. Chesselet, Production experimentale d'aérosols a la surface de la mer, J. Rech. Atmos., 8, 961, 1974.

Moyers, J. L., and R. A. Duce, Gaseous and particulate iodine in the marine atmosphere, J. Geophys. Res., 77, 5229, $1972 a$.

Moyers, J. L., and R. A. Duce, Gaseous and particulate bromine in the marine atmosphere, J. Geophys. Res., 77, 5350, $1972 b$.

Rahn, K. A., R. D. Borys, and R. A. Duce, Tropospheric halogen gases: Inorganic and organic components, Science, 192, 549, 1976.

Rancher, J., Contribution a l'etude du cycle du chlore, du brome et de l'iode dans l'atmosphère au-dessus de l'océan, thèse de troisième cycle, Univ. de Paris VII, Paris, 1978.

Robbins, R. C., R. D. Cadle, and D. L. Eckhard, The conversion of sodium chloride to hydrogen chloride in the atmosphere, J. Meteorol., 16, 53, 1959.

Schooley, A. H., Evaporation in the laboratory and at sea, J. Mar. Res., 27, 335, 1969.

Sehmel, G. A., and S. L. Sutter, Particle deposition rates on a water surface as a function of particle diameter and air velocity, $J$. Rech. Atmos., 8, 911, 1974.

Seto, F. Y. B., and R. A. Duce, A laboratory study of iodine enrichment on atmospheric sea salt particles produced by bubbles, $J$. Geophys. Res., 77, 5339, 1972.

Toba, Y., On the giant sea-salt particles in the atmosphere, 1, General features of the distribution, Tellus, 17, 131, 1965.

Wilkness, P. E., and D. J. Bressan, Fractionation of the elements F, $\mathrm{Cl}, \mathrm{Na}$, and $\mathrm{K}$ at the sea-air interface, J. Geophys. Res., 77, 5307, 1972.

Woodcock, A. H., Salt nuclei in marine air as a function of altitude and wind force, J. Meteorol., 10, 362, 1953.

Zafiriou, O. C., Photochemistry of halogens in the marine atmosphere, J. Geophys. Res., 79, $2730,1974$.

(Received May 24, 1979;

revised September 21, 1979; accepted November 29, 1979.) 